\title{
The Effects of Floral Arrangement on the Stress Index of the Elderly with Chronic Diseases and Its Correlation with Cognition
}

\author{
Byung Jin Choi, Yeon Hee Kim, and Suk Young Yun* \\ Department of Horticulture, Daegu Catholic University, Gyeongsan 38430, Korea
}

\begin{abstract}
This study aims to see what changes flower arrangement programs bring to the stress index of elderly people with chronic diseases and its correlation with cognition. Furthermore, seniors from a day care center and a nursing home were compared for the purpose of identifying the effectiveness of flower arrangement activities as a supplementary remedy designed to relieve the symptoms and improve the quality of life of patients with chronic diseases. In this study, 24 seniors with chronic diseases were divided into two groups: Group A consists of 15 seniors from a day care center and Group B consists of nine seniors from a nursing home. Both groups participated in simple flower arrangement activities in 10 sessions. In each session, red and green cut flowers that were preferred by the elderly were provided to elicit and develop their thoughts and behaviors. The results showed that the overall average stress index was significantly reduced from $58.0 \pm 11$. 6 before the program to $50.6 \pm 17.1$ after the program $(p=.037)$. This study examined that the program was more effective for Group A $(p=.021)$ than for Group B $(p=$ .678). Results of the correlation analysis showed that there was no correlation between cognitive function and stress index ( $p=.569)$, but that the activity was more effective for Group A. This study shows that arranging flowers effectively lowers the stress index of elderly people with chronic diseases. Also, sharing the outcomes of such activities with others or continuously caring for the flowers even after the activity can maximize the effectiveness of the therapy and rehabilitation. Thus, the study concluded that the program needs to be applied continuously, not in the short-term, in order to relieve or treat the symptoms of elderly patients with chronic diseases.
\end{abstract}

Keywords: care facilities, cut flowers, green, red

\section{Introduction}

With the population rapidly aging, senior citizens with chronic diseases are on the rise. The chronic disease prevalence rate of the elderly has reached $88.5 \%$, a very high level, and the multi-morbidity rate of the elderly has increased to $68.3 \%$, which indicates that more than half of the elderly population have at least two chronic diseases (Korea Institute for Health and Social Affairs, 2011). Most elderly people experience various problems such as the loss of health due to their deteriorating physical functions; poverty, the deprivation of social participation and changes in their position and role from a social and economic perspective; and loss of zest in life and the fear of death, and despondency from retire-

This paper was funded by the research funds of Daegu Catholic University in 2017.

Received: February 15, 2019, Revised: March 14, 2019, Accepted: May 2, 2019

First author: Byung Jin Choi, E-mail: bjchoi@cu.ac.kr, (1) https://orcid.org/0000-0001-8983-544X

*Corresponding author: Suk Young Yun, E-mail: yunesy@hanmail.net, (1) https://orcid.org/0000-0002-5862-0021 
ment from a psychological perspective (Kim, 2001). In particular, elderly people experience psychological withdrawal and extreme mental stress due to limited physical functions and pain when their health deteriorates due to chronic diseases (Kim and Choi, 2007).

Most of the stress that the elderly experience is caused by minor events in daily life, and is affected by little and chronic things (Tak, 2006). Stress that people experience chronically results in physical and mental disorders, which has a negative impact on the health and wellbeing of the elderly and on their successful aging (Koo et al., 2014). Their dependence increases due to their deteriorating physical and mental functions, and changes in people's perception of family support and decrease in their ability to support family members caused by urbanization and nuclearization are expressed as problems of the elderly, which resulted in an increasing number of elderly care facilities (Lee, 2007).

Patients with chronic diseases who use elderly care facilities use complementary and alternative therapies, expecting the relief of symptoms, improvement in quality of life and various effects of complementary therapies (Richardson, 2004). Regular physical activities have a positive impact on individuals' physical and mental state, and physical activities not only enhance the physical strength of the elderly, but also serve as a mean to improve their confidence and quality of life (Lee, 2013).

Horticultural activities using plants started to be used as a therapy, as stable environments that nature give are expected to improve the mental stability of those who participate in horticultural activities (Simson and Straus, 1997). Horticultural therapy stimulates the five senses of people using plants as a medium, and is known to be effective for those with mental disorders (Cho et al., 2003). Since horticultural activities involve many sensory organs including the eyes, nose, hands and brain, their effects are different from other therapies (Son, 1997). An earlier study reported that horticultural activities that used flower decorations increased the stability of participants and effectively reduced their level of stress (Tak, 2004). Flower decorations involve various actions such as trimming, cutting, bending and putting flowers, making knots and tying strings, which gave a sense of emotional stability and relieved stress (Jeong and Han, 2008). In particular, horticultural activities are effective in reducing the level of stress and cortisol hormone in the blood of patients with dementia (Yun and Choi, 2010), and various horticultural therapy programs focusing on sensory stimulation were also reported as an effective therapeutic program in improving elderly people's quality of life in aging society (Yun et al., 2010).

Against this backdrop, this study aimed to examine what kind of changes flower arrangement activities give to the stress index of the elderly with chronic diseases. In order to identify the effectiveness of horticultural activities as a complementary therapy to relieve the symptoms of those with chronic diseases who use elderly care facilities and to improve their quality of life, elderly people who used an elderly care facility were divided into those who used it during the day time and those who used it during the day and night time.

\section{Research Methods}

\section{Subjects}

This study was conducted on elderly patients with chronic diseases who were cared due to symptoms of dementia and stroke at an senior welfare center located in D city. A total of 29 elderly patients who wanted to participate in this program were selected, and an approval for the participation of each patient was obtained from the head of the center and their guardian. A total of 24 patients who participated in the program without being absent were selected as the final subjects, and they were divided into those who used the center during the day time (15 patients, Group A), and those who were admitted to the nursing home (nine patients, Group B). Group A was composed of two males and 13 females, and their average age was 83.6. Group B was composed of nine females, and their average age was 83.4. 
Tools

\section{Program design}

The activity of making a flower basket was reported to show the highest emotional response, and colorful flowers were also reported to improve the emotional stability of the elderly and reduce their depression (Lee et al., 2000). The results of a survey on the color of flowers preferred by the elderly showed that they preferred red the most (Kim et al., 2018). Red is known to provide an emotional background that can draw thoughts and actions, and green is suitable to develop these thoughts and actions and execute them (Yun, 2006). Kim et al. (2018) designed a horticultural activity program in which warm colors and cold colors were evenly used in each session, and reported that activities of putting flowers into a designated space improved the visual perception and motor coordination skills of participants. In this regard, this study designed a flower arrangement program of 10 sessions, and instructed participants to put cut flowers into a designated floral foam $(9.5 \times 7.5 \times 6 \mathrm{~cm})$ (Kim et al., 2018). Instructions on the length of flowers were provided only, and participants were allowed to put flowers freely regardless of the location and angle of flowers. In each session, red and green-colored plants were provided basically, and red plants included 'Rosa hybrida,' 'Gerbera jamesonii' and 'Dianthus caryophyllus' and green plants included 'Chamaecyparis obtusa.' To fill up the blanks, pink and white plants (Alstroemeria aurantiaca), yellow plants (Freesia hybrida, Chrysanthemum morifolium) and purple plants (Eustoma grandiflorum) were also provided (Table 1).

\section{Program execution}

This study was conducted by dividing subjects into two groups: those who used the center during the day time only and go back home in the evening (Group A) and those who were admitted to the center and used the center during the day and night time. The program designed in this study was performed once a week on Thursday from February 1 to April 30, 2018, a total of 10 sessions. Group A (senior day care center) participated in the program between 11:00 and 12:00 and Group B (nursing home) participated in the program between 13:00 and 14:00 for 60 minutes. The sessions were provided at a program room $\left(33 \mathrm{~m}^{2}\right)$ within a senior welfare center located in D city. They were led by one Grade-1 welfare horticultural therapist (certified by the Korean Horticultural Therapy Association) and were assisted by one social worker and four care workers.

Table 1. Cut flowers by color used in the flower arrangement program

\begin{tabular}{lccc}
\hline Session & \multicolumn{2}{c}{ Cut flower by color } & \\
\hline 1 & Red & Green & Other colors \\
2 & Rosa hybrida & Chamaecyparis obtusa & Alstroemeria aurantiaca (pink) \\
3 & Gerbera jamesonii & Chamaecyparis obtusa & Freesia hybrida (yellow) \\
4 & Rosa hybrida & Chamaecyparis obtusa & Chrysanthemum morifolium (yellow) \\
5 & Dianthus caryophyllus & Chamaecyparis obtusa & Freesia hybrida (yellow) \\
6 & Rosa hybrida & Chamaecyparis obtusa & Alstroemeria aurantiaca (pink) \\
7 & Gerbera jamesonii & Chamaecyparis obtusa & Chrysanthemum morifolium (yellow) \\
8 & Rosa hybrida & Chamaecyparis obtusa & Freesia hybrida (yellow) \\
9 & Dianthus caryophyllus & Chamaecyparis obtusa & Alstroemeria aurantiaca (white) \\
10 & Rosa hybrida & Chamaecyparis obtusa & Eustoma grandiflorum (purple) \\
\hline
\end{tabular}




\section{Assessment tools}

To measure the level of stress in the autonomic nervous system, uBioMacpa v70 (BioSense Creative, Korea) was used. uBioMacpa v70 measures pulse waves at the capillaries in the fingertips in a non-invasive manner, and analyzes the pulse variability of the heart. With the pulse wave detector, you can measure the level of stress of the body and identify any abnormal condition in the autonomic nervous system. uBioMacpa v70 measures the level of stress based on the guidelines on average pulse variability signal analysis issued the North American Society of Pacing and Electrophysiology and the European Society of Cardiology (Vanderlei et al., 2009). Since the measured pulse variability of the autonomic nervous system is affected by even a small movement, the level of stress was measured with a hand fixed on a pad in a seated position for 2 minutes 30 seconds after completing horticultural activities.

In this study, the cognitive functions of subjects was used not to identify the effectiveness of horticultural activities, but to examine the characteristics of the two groups. Data that are measured regularly by the senior welfare center every month to observe changes in the cognitive functions of patients were utilized, and the Mini-Mental State Examination (MMSE) that was developed by Folstein et al. (1975) and translated into Korean by Kwon and Park (1989) was used as a measuring tool. The Korean-Mini-Mental State Examination (K-MMSE) is a tool to measure the cognitive functions of the elderly including orientation, attention and calculation, language function and judgement, and the closer the score is to 30 , the higher the level of cognitive functions. The Cronbach's $\alpha$ value in this study was .86 .

\section{Data analysis}

Data measured before and after the program were analyzed using IBM SPSS Statistics 19 Program. The homogeneity of Groups A and B was analyzed using the Mann-Whitney U test, and differences in the stress index between before and after the program were verified using the Wilcoxon-signed rank test. The correlation between cognitive function and stress index was analyzed using the Spearman's rank correlation analysis.

\section{Results and Discussion}

\section{Homogeneity test between groups}

Prior to providing the program, the homogeneity of Group A (senior day care center) and Group B (nursing home) was verified by conducting the Mann-Whitney test on the age of subjects, the Mini-Mental State Examination (MMSE) and the stress index, a dependent variable in this study. The average age of Group A and Group B was 83.6 \pm 4.8 and $83.4 \pm 5.9$ respectively, showing no statistically significant difference $(p=.907)$, which indicated that the two groups were homogeneous. The cognitive function of Group A (19.3 \pm 4.9$)$ of which subjects used the day care center was higher than that of Group B $(14.2 \pm 1.2)(p=.018)$. However, there was no statistically significant difference in the stress index (dependent variable) between Group A (58.6 \pm 13.6$)$ and Group B $(57.1 \pm 7.7)(p=.519)$, which indicated that the two groups were homogeneous, and thus it was possible to verify the effectiveness of the stress index depending on each group's horticultural activities (Table 2).

\section{Changes in the stress index within groups}

Changes in the stress index of elderly patients with chronic diseases before and after participating in horticultural activities were examined by measuring conditions of the autonomic nervous system. The stress index is calculated by combining pulse variability (pulse diversity), sympathetic activation, parasympathetic activation, autonomic balance, 
average pulse rates, standard deviation of pulse rates, and average deviation, and Table 3 shows the stress index of Groups A and B measured using uBioMacpa. The stress index of Group A (senior day care center) statistically significantly decreased from $58.6 \pm 13.6$ before participating in the program to $47.2 \pm 18.7$ after participating in the program ( $p=.021$ ), and that of Group B (nursing home) did not show any statistically significant difference between before participating in the program (57.1 \pm 7.7$)$ and after participating in the program $(56.2 \pm 12.8)(p=.678)$. To examine overall changes in the stress index of all the elderly patients with chronic diseases surveyed in this study, the results of Groups A and B were analyzed together, and the stress index statistically significantly decreased from $58.0 \pm 11.6$ before participating in the program to $50.6 \pm 17.1$ after participating in the program $(p=.037)$.

These results coincided with the results of earlier studies. Jang et al. (2019) reported that the stress index of patients with brain diseases obtained by measuring the autonomic nervous system significantly decreased after participating in horticultural activities, and Yun and Choi (2010) also reported that the level of cortisol, a stress hormone, in the blood of elderly patients with dementia significantly decreased after participating in flower decoration activities that they preferred. The results were also similar to the result of Jang (2008) that plants in patients' room decreased the cortisol level in the blood of patients who underwent a surgery and were hospitalized, and the result of Goodwin et al. (1994) that seeing green plants or flowers was effective in relaxing people's mental state and reducing their stress level. They are also in the same line with the results of other studies that horticultural activities such as planting plants allowed people to perceive the passage of time through changes in plants and that learning and using names of various plants relieved the tension, reduced the level of stress and restore psychological stability (Talbott et al., 1976; Ulrich, 1981).

\section{Changes in the stress index between groups}

Changes in the stress index of elderly patients with chronic diseases after participating in horticultural activities were examined by measuring changes in the stress index. The stress index of Group A (senior day care) and Group B (nursing home) after participating in horticultural activities was analyzed through the Mann-Whitney post-hoc test. The stress

Table 2. Pre-homogeneity test of the Group A(senior day care) and Group B(nursing home) participants

\begin{tabular}{|c|c|c|c|c|c|c|c|}
\hline \multirow{2}{*}{ Item } & \multirow{2}{*}{ Unit } & \multicolumn{2}{|c|}{ Group A } & \multicolumn{2}{|c|}{ Group B } & \multirow{2}{*}{ z } & \multirow{2}{*}{$p$} \\
\hline & & M & SD & M & SD & & \\
\hline Age & Years & 83.6 & 4.8 & 83.4 & 5.9 & -0.120 & $.907^{\mathrm{NS}}$ \\
\hline MMSE & Score & 19.3 & 4.9 & 14.2 & 3.7 & -2.339 & $.018^{*}$ \\
\hline Stress index & - & 58.6 & 13.6 & 57.1 & 7.7 & -0.686 & $.519^{\mathrm{NS}}$ \\
\hline
\end{tabular}

Note. MMSE=Mini-Mental State Examination.

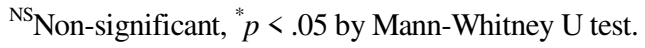

Table 3. Comparisons of the stress index of participants before and after horticultural activity program

\begin{tabular}{lcccc}
\hline Group & Before horticultural activity & After horticultural activity & $\mathrm{z}$ & \multicolumn{1}{c}{} \\
\hline A (senior day care) & $58.6 \pm 13.6$ & $47.2 \pm 18.7$ & -2.302 & $.021^{*}$ \\
B (nursing home) & $57.1 \pm 7.7$ & $56.2 \pm 12.8$ & -0.415 & $.678^{\mathrm{NS}}$ \\
Total (A+B) & $58.0 \pm 11.6$ & $50.6 \pm 17.1$ & -2.086 & $.037^{*}$ \\
\hline
\end{tabular}

${ }^{\mathrm{NS}}$ Non-significant, ${ }^{*} p<.05$ by Wilcoxon-signed rank test. 
index, an dependent variable, of Group A and Group B was 47.2 \pm 18.7 and 56.2 \pm 12.8 respectively, showing a statistically significant difference ( $p=.043$ ), which indicated that there were differences in the stress index between groups (Table 4). In other words, the stress index of those in Group A who used the facility during the day time only significantly decreased compared to those in Group B who could not go back home. The observation log of each subject written by therapists during each session was analyzed. It was found that subjects in Group A who used the facility during the day time only took the outcome of each activity home after each session, and shared and talked about the experience with their family members, and praises from their family members seemed to encourage them to actively participate in the program.

\section{Correlation between cognitive function and stress index}

This study divided patients with chronic diseases who used an elderly care facility into those who used the facility during the day time only (Group A) and those who were admitted to and used the facility during the day and night time (Group B), and examined changes in their stress index by group after participating in horticultural activities. The effectiveness of horticultural activities in Group A and Group B was different (Tables 3 and 4). Since the cognitive function of the two groups was found to be different in the homogeneity test conducted prior to providing the program (Table 2), the Spearman's serial correlation analysis was conducted to identify whether the cognitive function caused changes in the stress index by ranking the degree of decrease in the cognitive function and stress index of subjects. The cognitive function and stress index had a positive correlation (correlation coefficient $=.122, p=.569$ ), but showed no significance (Table 5). This indicates that the decreasing stress index can be contributed to the horticultural activities performed for one hour per week themselves, but sharing the outcome of the activities with family members seemed to be also contributed to the decrease, rather than the cognitive function of subjects.

In this study, red flowers that elderly people prefer and can draw thoughts and actions were provided in each session

Table 4. Post homogeneity test of the Group A (senior day care) and Group B (nursing home)

\begin{tabular}{|c|c|c|c|c|c|c|c|}
\hline \multirow{2}{*}{ Item } & \multirow{2}{*}{ Unit } & \multicolumn{2}{|c|}{ Group A } & \multicolumn{2}{|c|}{ Group B } & \multirow{2}{*}{$\mathrm{z}$} & \multirow{2}{*}{$p$} \\
\hline & & M & SD & M & SD & & \\
\hline Stress index & - & 47.2 & 18.7 & 56.2 & 12.8 & -0.955 & $.043^{*}$ \\
\hline
\end{tabular}

${ }^{*} p<.05$ by Mann-Whitney $\mathrm{U}$ test.

Table 5. Correlation between cognitive function (MMSE) and stress index

\begin{tabular}{|c|c|c|c|}
\hline Variable & & Stress Index & MMSE \\
\hline \multirow{3}{*}{ Stress index } & Pearson correlation coefficient & 1 & .122 \\
\hline & $p$ & & .569 \\
\hline & $\mathrm{n}$ & 24 & 24 \\
\hline \multirow{3}{*}{ MMSE } & Pearson correlation coefficient & .122 & 1 \\
\hline & $p$ & .569 & \\
\hline & $\mathrm{n}$ & 24 & 24 \\
\hline
\end{tabular}

Note. MMSE = Mini-Mental State Examination 
in order to induce their active participation. Although they lost self-confidence due to their chronic diseases, they had a stronger desire for colorful flowers, which seemed to make them actively participate in the flower arrangement activity despite difficulties in moving their body. These results coincided with the results of earlier studies that horticultural activities were effective in reducing the depression of elderly people (Yun et al., 2003), and improving the psychological stability of elderly patients who used care facilities (Barnicle and Midden, 2003). They were also similar to the results of other studies that horticultural therapy programs using flower decorations were very effective in controlling emotional balance and reducing depression for hospitalized patients who needed to be treated in a comfortable indoor space (Yun et al., 2009), and that using flower decorations that were preferred by elderly people only was effective not only in causing changes in the subjective stress level but also in reducing the cortisol hormone in the blood, which improved emotional stability (Yun and Choi, 2010).

When programs are operated for elderly people, simple, repetitive horticultural activities instead of various activities can give them a sense of confidence and satisfaction (Kim, 2003), and have a better therapeutic effect. In this study, repetitive activities of putting flowers in a floral foam encouraged elderly patients to more actively participate in the activities and show higher self-confidence over time, which was expressed as various past memories, and actions of helping others.

\section{Conclusion}

This study aimed to examine changes in the stress index of elderly people with chronic diseases. A total of 24 elderly people with chronic diseases were divided into two groups: Group A was composed of 15 elderly people who used the day care center, and Group B was composed of nine elderly people who were admitted to the nursing home. Activities of flower arrangement were repeated in 10 sessions. Participants were instructed to pick flowers of designated colors and cut them to a certain length, and were allowed to freely put the cut flowers in a floral foam of a certain size. The overall average stress index of the participants significantly decreased from $58.0 \pm 11.6$ before participating in the activities to 50.6 \pm 17.1 after participating in the activities $(p=.037)$. In particular, the activities were more effective for those in Group A who were able to take the outcome of the activities home and share it with family members $(p=.021)$ than those in Group B who stayed at the care facility $(p=.678)$. This study examined whether differences in the stress index between the two groups were related to the cognitive function of participants, but there was no correlation between the stress index and cognitive function of participants. The observation log of each participants written subjectively showed that sharing the outcome of activities with family members seemed to contribute to the differences. In this study, flower arrangement activities were performed only, but, in follow-up studies, various horticultural activities using plants can be applied according to the purpose of treatment for different groups of subjects. As the results of this study showed, the therapeutic effects of horticultural activities seem to be maximized not by simply participating in activities, but also by sharing the outcomes of the activities with someone to give participants time to continuously commune with plants. The overall quality of life of elderly people with chronic diseases is expected to be improved by developing various programs, differentiated programs and selective programs.

\section{References}

Barnicle, T. and K.S. Midden. 2003. The effects of horticulture activity program on the psychological well-being of older people in a long term care facility. HortTechonology 13(1):81-85. https://doi.org/10.21273/HORTTECH.13.1.0081

Cho, M.K., S.I. Jung, K.C. Son, and M.K. Kim. 2003. Effect of phased application of horticultural therapy programs 
on improvements of assertiveness and interpersonal relationship of chronic schizophrenia. J. Korean Soc. Hortic. Sci. 44(6):972-979.

Folstein, M.F., S.E. Folstein, and P.R. McHugh. 1975. Mini-mental state: A practical method for grading the cognitive state of patients for the clinician. J. Paychiatr. Res. 12(3):189-198. https://doi.org/10.1016/0022-3956(75)90026-6

Goodwin, G.K., C.H. Pearson-Mims, and V.I. Lohr. 1994. The impact of adding interior plants to a stressful setting. In: M. France, J.S. Rice, and P. Lindsey (Eds.), Proceedings of a research symposium: The healing dimension of people-plant relations (pp. 353-362). UC Davis, CA: Center Design Research, Department of Environmental Design, University of California.

Jang, E.J., S.Y. Yun, B.J. Choi, and Y.G. Kim. 2009. The horticultural activity of touching soil and the autonomic nervous stress response of patients with brain disease. Hortic. Sci. Technol. 37(1):151-158. https://doi.org/10.12972/kjhst.20190014

Jang, J.G. 2008. Effect of indoor plants in hospital rooms on the reducing of cortisol of inpatients. Master's thesis, Gyeongsang National University, Jinju, Korea.

Jeong, H.I. and I.J. Han. 2008. A study on the methodology of analysis for the five senses development of children by flower arrangement. J. Korean Soc. Flor. Art Des. 18:89-118.

Kim, D.H. 2001. A study on the correlation among family support, self-esteem and depression in elderly. Korean J. Gerontol. Soc. Welf. 13:113-143.

Kim, H.Y. 2003. Theory and practice of horticultural therapy. Daegu, Korea: Korea Horticultural Therapy Research Center.

Kim, S.H. and Y.H. Choi. 2007. The influence of physical health on suicidal ideation in older adults. J. Korean Gerontol. Soc. 27(4):775-788.

Kim, Y.H., S.Y. Yun, and B.J. Choi. 2018. The effects of the floral arrangement in a designated space on the visual perception motor coordination ability and hand function of the elderly with dementia. J. People Plants Environ. 21(3): 213-221. https://doi.org/10.11628/ksppe.2018.21.3.213

Koo, C.Y., J.S. Kim, and J.O. Yu. 2014. A study on factors influencing elders' suicidal ideation: Focused on comparison of gender differences. J. Korean Acad. Community Health Nurs. 25(1):24-32.

https://doi.org/10.12799/jkachn.2014.25.1.24

Korea Institute for Health and Social Affairs. 2011. Health conditions of the aged and policy development. Health and welfare policy issues 2011. Sejong, Korea: Author.

Kwon, Y.C. and J.H. Park. 1989. Korean version of mini-mental state examination (MMSE-K). Part I: Development of the test for the elderly. J. Korean Neuropsychiatr. Assoc. 28(1):125-135.

Lee, M.H., S.H. Park, S.Y. Lim, E.K. Jeong, and J.K. Suh. 2000. A study for preference of older adult about horticultural therapy programs. J. Korean Soc. People Plants Environ. 3(4):31-37.

Lee, S.G. 2013. The effects of elderly women's participation in physical activity on her basal physical fitness, depression and self-esteem. Master's thesis, Inha University, Incheon, Korea.

Lee, S.H. 2007. A study on the operation status and improvement plan of the elderly daycare facilities. Master's thesis, Inha University, Incheon, Korea.

Richardson, J. 2004. What patients expect from complementary therapy: A qualitative study. Am. J. Public Health 94(6): 1049-1053.

Simson, S. and M.C. Straus (Eds.). 1997. Horticulture as therapy: Principles and practice. Binghamton, NY: The Food Products Press.

Son, K.C. 1997. Study on the effects of indoor plants on human brain waves. Seoul, Korea: Central life cycle.

Tak, S.H. 2006. An insider perspective of daily stress and coping in elders with arthritis. Orthop. Nurs. 25(2):127-132.

Talbott, J.A., D. Stern, J. Ross, and C. Gillen. 1976. Flowering plants as a therapeutic/environmental agent in a psychiatric hospital. HortScience 11(4):365-366.

Ulrich, R.S. 1981. Natural versus urban scenes: Some psychophysiological effects. Environ. Behav. 13(5):523-556. 
https://doi.org/10.1177/0013916581135001

Vanderlei, L.C., C.M. Pastre, R.A. Hoshi, T.D. Carvalho, and M.F. Godoy. 2009. Basic notions of heart rate variability and its clinical applicability. Rev. Bras. Cir. Cardiovasc. 24(2):205-217. https://doi.org/10.1590/S0102-76382009000200018

Yun, H.R. 2006. Colorist synthesis theory. Seoul, Korea: International Book Publishing Co.

Yun, S.Y. and B.J. Choi. 2010. Effect of horticultural therapy on the stress and serum cortisol of demented elders. Korean J. Hortic. Sci. Technol. 28(5):891-894.

Yun, S.Y., B.J. Choi, and H.Y. Kim. 2009. The effects of flower arrangement on the balance of feelings and depression of hospitalized elders. J. Korean Soc. People Plants Environ. 12(6):1-5.

Yun, S.Y., H.Y. Kim, and J.K. Kim. 2003. Effect of horticultural therapy on the decrease of depression of the old adults (Abstr.). Korean J. Hortic. Sci. Technol. 21(Suppl. II):34.

Yun, S.Y., K.O. You, B.J. Choi, and H.Y. Kim. 2010. Effects of the horticultural therapy on choice reaction and cognitive function of nursing home elders. J. Korean Soc. People Plants Environ. 13(4):23-28. 